\title{
Effect of different solid medium on blueberry soilless culture
}

\author{
Xun Wang ${ }^{1}$, Yanan Wang ${ }^{2}$, Jun Wang ${ }^{2^{*}}$ \\ 1: Institute of Pomology \& Olericulture, Sichuan Agricultural University, Chengdu, Sichuan, China \\ 2: College of Horticulture, Sichuan Agricultural University, Chengdu, Sichuan, China \\ *Corresponding author: 4692670@qq.com
}

Keywords: blueberry; solid medium; soilless culture; plant development

Abstract. Six solid media, including rice hull, sawdust, wood chips, plastic pellet, coir and perlite, mixed with peat were used for blueberry 'Sharpblue' soilless culture. We determined the plant growth and development to estimate the optimal solid medium for blueberry soilless culture.

\section{Introduction}

Blueberry (Vaccinium spp.) has high medical and economic value, and is called "the king of berries" ${ }^{[1]}$. Blueberry planting is increasing in recent years, since it shows high economic value ${ }^{[2-4]}$. However, blueberry growth strictly required soil environment, as blueberry has fibrous root system, and the root is thin and no root hair ${ }^{[5]}$. Soil acidic $(\mathrm{pH} 4.0 \sim 5.5)$ and rich in organics $(>5 \%)$ is the favorable soil for blueberry growth ${ }^{[6]}$. Soilless cultivation, using solid media to replace soil, is an optional way to plant blueberry. In this study, we used six solid media, e.g. rice hull, sawdust, wood chips, plastic pellet, coir and perlite, mixed with peat to investigate the effect of soilless cultivation performed on blueberry. This research is expected to be applied in blueberry agricultural production.

\section{Material and methods}

Material

The blueberry northern high bush cultivar 'Sharpblue' was used. The blueberries were planted in pots, and put in Sichuan Agricultural University (Chengdu campus) greenhouse.

Solid media preparation

Rice hull, sawdust, wood chips, plastic pellet, coir and perlite were used. The six solid media were mixed with peat $1: 1$ by volume. The mixed media were added sulfur $10 \mathrm{~g}$ powder to reduce $\mathrm{pH}$ value to be favorable level. Three pots, regarded as 3 repetitions, were set for each solid medium. Plant growth determination

The plant growing properties, including plant height, tree crown diameter, stem diameter and branch length, were determined once every 15 days. The determination was from $1^{\text {st }}$ march, and performed five times.

\section{Results}

The physical properties of solid media

The physical properties of solid media were in Table 1. Sawdust showed highest bulk density of $0.25 \mathrm{~g} / \mathrm{cm}^{-3}$, and plastic pellet was the media with lowest bulk density. From total porosity, plastic 
pellet showed lowest value (48.28\%), while rice hull and coir displayed high porosity, $87.36 \%$ and $89.53 \%$ respectively. Total porosity is detailed into air porosity and water porosity. Sawdust and coir showed significant low air porosity, but relatively high water porosity. Comparatively, plastic pellet displayed significant low water porosity, but its air porosity was not too low. On the other hand, rice hull showed the highest air porosity but low water porosity. Comparing the air/water porosity ratios of all solid media, sawdust and coir have significant low air/water ratios, 0.05 and 0.04 respectively, and plastic pellet has the highest air/water ratio (13.00).

Table 1 The physical characters of solid media

\begin{tabular}{|c|c|c|c|c|c|}
\hline substrate & $\begin{array}{l}\text { Bulk density } \\
\left(\mathrm{g} / \mathrm{cm}^{-3}\right)\end{array}$ & Total porosity $\%$ & Air porosity \% & Water porosity $\%$ & Air/water ratio \\
\hline rice hull & 0.10 & 87.36 & 72.41 & 14.94 & 4.85 \\
\hline sawdust & 0.25 & 73.56 & 3.45 & 70.11 & 0.05 \\
\hline wood chips & 0.12 & 78.16 & 58.62 & 19.54 & 3.00 \\
\hline plastic pellet & 0.02 & 48.28 & 44.83 & 3.45 & 13.00 \\
\hline coir & 0.16 & 89.53 & 3.49 & 86.05 & 0.04 \\
\hline perlite & 0.09 & 71.26 & 42.53 & 28.74 & 1.48 \\
\hline
\end{tabular}

Effect of different solid media on blueberry plant height

From Fig. 1, blueberry plant growing in coir showed best plant height development. At the same time, blueberry plant growing in wood chips, plastic pellet and perlite showed retively high plant development. The blueberry plant growing in sawdust and rice hull showed retively worse development than in other solid media.

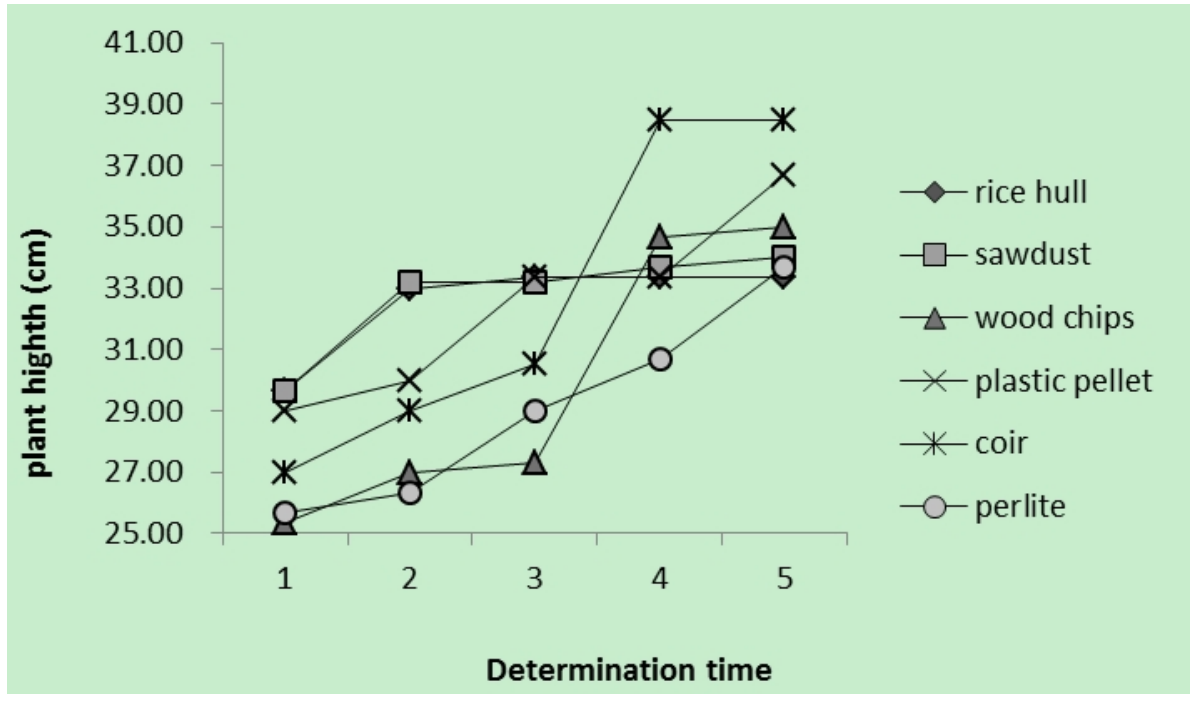

Fig. 1 Effect of different solid media on blueberry plant height

Effect of different solid media on blueberry tree crown diameter

The development of tree crown diameter in different solid media was in Fig. 2. Developments lined from best to worst were in coir, rice hull, perlite, plastic pellet, wood chips and sawdust. The plant growing in coir showed best growth in tree crown diameter, especially during $3^{\text {rd }}$ and $4^{\text {th }}$ experimental determination. The plant growing in sawdust showed worst growth in tree crown diameter. The development was always low with light increasing. 


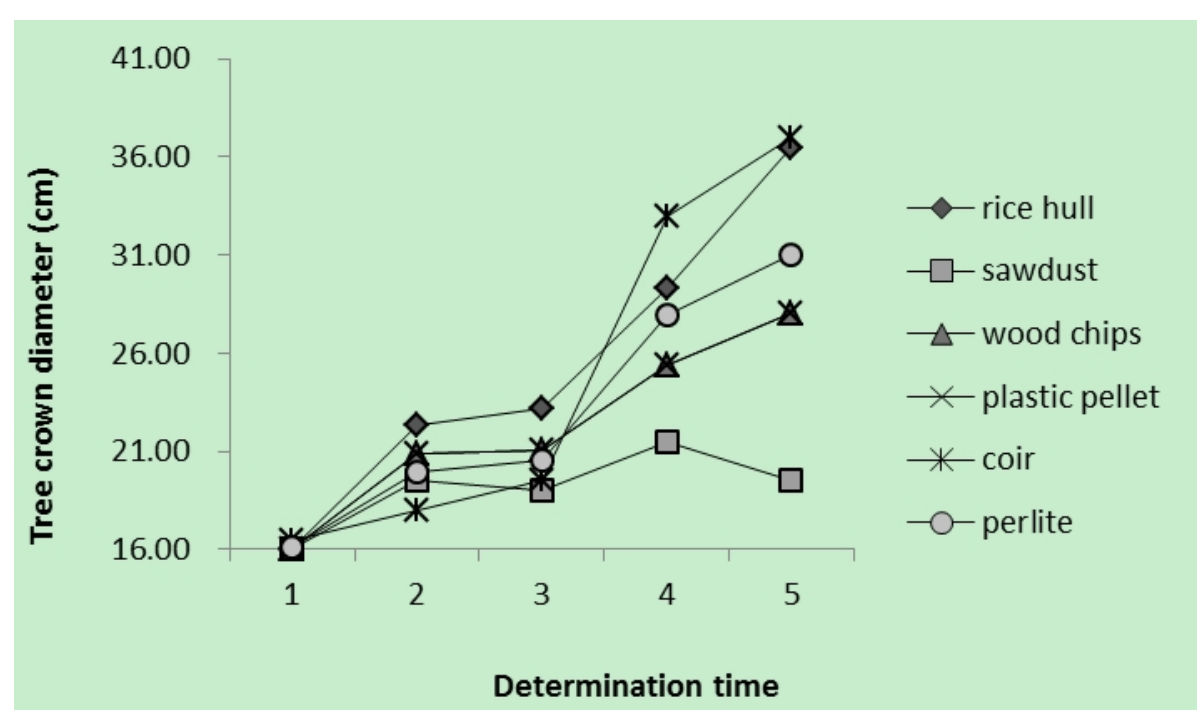

Fig. 2 Effect of different solid media on blueberry tree crown diameter

Effect of different solid media on blueberry stem diameter

The development of blueberry stem diameter in different solid media was in Fig. 3. The development of stem diameter growing sawdust was the best, especially during the beginning of plant growth. Plants growing in rice hull, plastic pellet and coir showed similar development in stem diameter. The plant growing in wood chips was slow in the beginning, but increased development during the $3^{\text {rd }}$ and $4^{\text {th }}$ determination. Blueberry growing in perlite showed worst development in stem diameter.

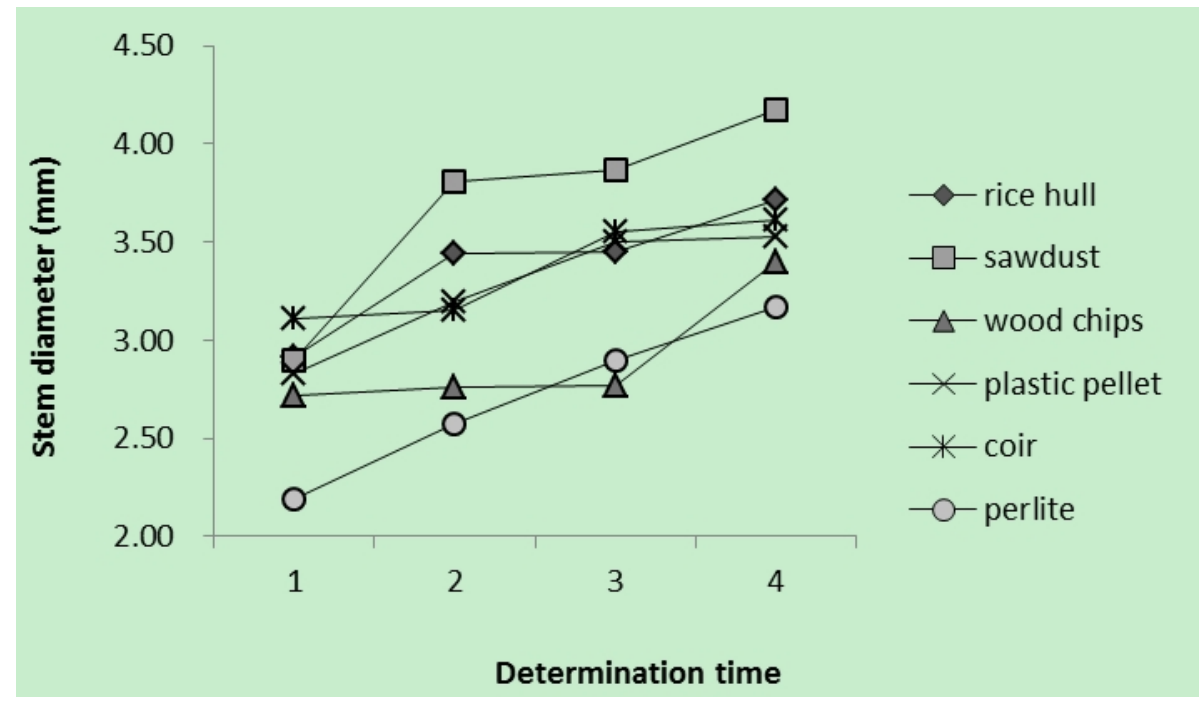

Fig. 3 Effect of different solid media on blueberry stem diameter

Effect of different solid media on blueberry branch length

The development of plant branch length was showed in Fig. 4. All plants showed significant increasing development in plant branch length. The plants growing in plastic pellet, coir and wood chips developed better than the plants growing other tree solid media, as the growth rates were higher. The plants growing in rice hull, sawdust and perlite showed relatively steady development in branch length. 


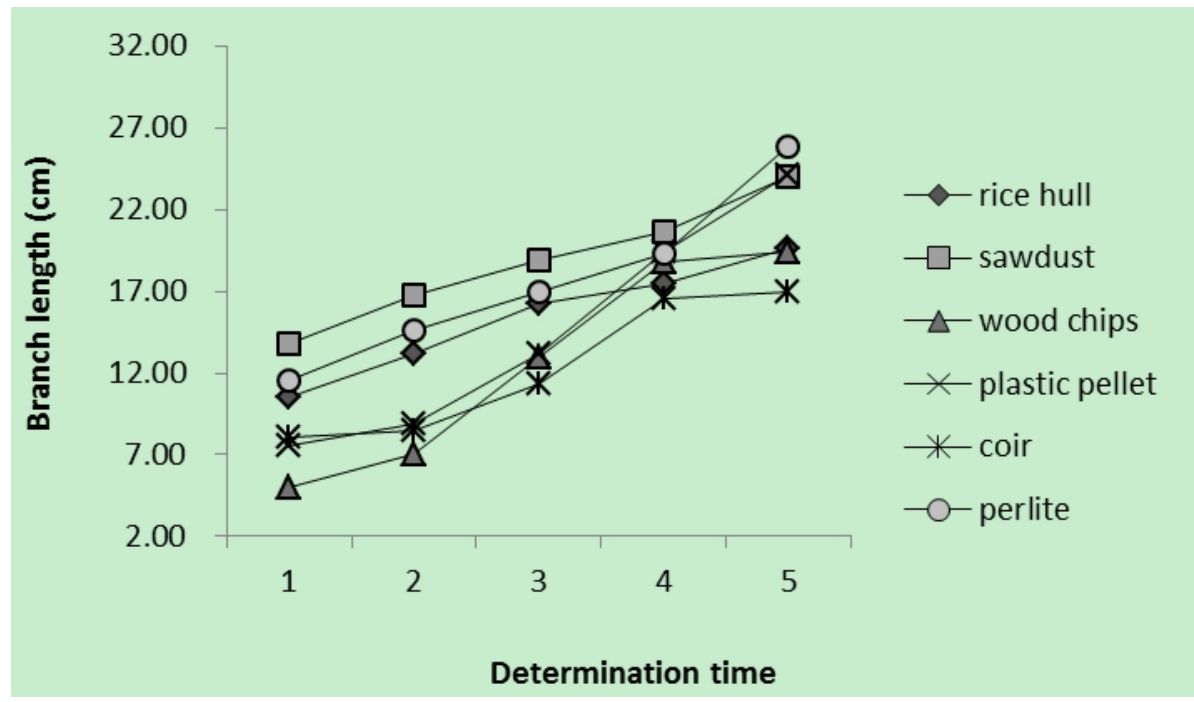

Fig. 4 Effect of different solid media on blueberry branch length

\section{Discussion}

The substrates of small bulk density are easy to operate and it is helpful to reduce transportation cost ${ }^{[7]}$. In our study, expected for plastic pellet, the total porosity of solid media were all in the range of $60 \%-90 \%$, which is an ideal porosity support plant growth ${ }^{[8]}$. From the results, the plant height blueberry trees showed best performance in coir medium, tree crown diameter showed best performance also in coir medium, stem diameter showed best performance in sawdust medium, and branch length showed best performance in perlite medium. Summarily, coir medium was the best solid medium. Meanwhile, rice hull and perlite media could also support blueberry soilless growth well.

\section{References}

[1] Wang H, Wang PY, Wang S, et al. Status and prospect of blueberry in china. Agricultural Modernization, 2008, 29 (2): 250-253.

[2] Shi LC. Technology of blueberry in pot in hebei province. Hebei Fruit Tree, 2015 (2): 37-38.

[3] Joshi S, Howell AB, Dsouza DH. Blueberry proanthocyanidins against human norovirus surrogates in model foods and under simulated gastric conditions. Food Microbiology, 2016 (63):263.

[4] Rodriguez-Mateos A, Feliciano RP, Cifuentes-Gomez T, Jpe S. Bioavailability of wild blueberry (poly) phenols at different levels of intake. Journal of Berry Research, 2016, 6 (2):137-148.

[5] Qiao JL, Li Y, Wang CH, Xu J, Xiao YK. Effects of different drip irrigation methods on chlorophyll fluorescence characteristics and growth of greenhouse blueberry. China Rural Water and Hydropower, 2017, (09): 5-9.

[6] Wang L, Pan J, Wan ZB. Research and development of blueberry cultivation substrate and special nutrient substrate. Huangshan University, 2011,13 (05): 60-62.

[7] Wang LF, Pan B, Qi XX, Zhang JC, Deng T, Ou MW. Optimization screening of urethane cultivation substance for bovine ear. Northern Horticulture, 2017, (03): 76-80.

[8] Song ZG. Study on soilless culture substrate of tomato with different crop stalks. Chinese Academy of Agricultural Sciences, 2013. 